'Influence of dietary conjugated linoleic acid (CLA) on lipid and fatty acid composition in liver and flesh of Atlantic salmon (Salmo salar)' by Sean R.

Kennedy, Patrick J. Campbell, Allan Porter and Douglas R. Tocher. Comparative Biochemistry and Physiology Part B: Biochemistry and Molecular Biology, Volume 141, Issue 2, June 2005, pp. 168 - 178.

Published in Comparative Biochemistry and Physiology Part B: Biochemistry and Molecular Biology by Elsevier. Comparative Biochemistry and Physiology Part B: Biochemistry and Molecular Biology, Volume 141, I ssue 2, J une 2005, pp. 168 178.

This is the peer reviewed version of this article.

NOTICE: this is the author's version of a work that was accepted for publication in Comparative Biochemistry and Physiology Part B: Biochemistry and Molecular Biology. Changes resulting from the publishing process, such as peer review, editing, corrections, structural formatting, and other quality control mechanisms may not be reflected in this document. Changes may have been made to this work since it was submitted for publication. A definitive version was subsequently published in Comparative Biochemistry and Physiology Part B: Biochemistry and Molecular Biology, VOL 141, ISSUE 2, (June 2005). DOI 10.1016/j.cbpc.2005.02.010. 


\section{Influence of dietary conjugated linoleic acid (CLA) on lipid and fatty acid composition in liver and flesh of Atlantic salmon (Salmo salar)}

Sean R. Kennedy ${ }^{\mathrm{a}, *}$, Patrick J. Campbell ${ }^{\mathrm{b}}$, Allan Porter ${ }^{\mathrm{a}}$ and Douglas R. Tocher ${ }^{\mathrm{a}}$

${ }^{a}$ Institute of Aquaculture, University of Stirling, Stirling FK9 4LA, UK

${ }^{b}$ BioMar Ltd., Grangemouth Docks, Grangemouth FK3 8UL, Scotland, UK.

Keywords: CLA; lipid; fatty acid; composition; liver; flesh; Atlantic salmon

*, Correspondence to: Sean R Kennedy, Institute of Aquaculture, University of Stirling, Stirling FK9 4LA, United Kingdom. Tel. No: +44 1786 466599; Fax No: +44 1786 472133; Email: s.r.kennedy@stir.ac.uk 


\begin{abstract}
The aim of the present study was to determine the effects of conjugated linoleic acid (CLA) on lipid and fatty acid metabolism in Atlantic salmon. The overall objective being to test the hypotheses that CLA has beneficial effects in salmon including growth enhancement, improved flesh quality through decreased adiposity and lipid deposition thereby minimising detrimental effects of feeding high fat diets, and increased nutritional quality through increased levels of beneficial fatty acids including n-3 highly unsaturated fatty acids (HUFA) and CLA itself. Salmon smolts were fed diets containing two levels of fish oil (low, $\sim 18 \%$ and high, $\sim 34 \%$ ) containing three levels of CLA (a 1:1 mixture of 9cis,trans-11 and trans-10,cis-12. at 0,1 and $2 \%$ of diet) for 3 months and the effects on growth performance, liver and muscle (flesh) lipid contents and class compositions, and fatty acid compositions determined. The diets were also specifically formulated to investigate whether the effects of CLA, if any, were more dependent upon absolute content of CLA in the diet (as percentage of total diet) or the relative level of CLA to other fatty acids. Dietary CLA in salmon smolts had no effect on growth parameters or biometric parameters. However, there was a clear trend of increased total lipid and triacylglycerol contents in both liver and flesh in fish fed CLA, particularly in fish fed the high oil diets. Finally, CLA was incorporated into tissue lipids, with levels in flesh being 2-fold higher than in liver, but importantly, incorporation in liver was at the expense of saturated and monounsaturated fatty acids whereas in flesh it was at the expense of n-3HUFA.
\end{abstract}




\section{Introduction}

Lipids and their constituent fatty acids are, along with proteins, the major organic constituents of fish, with carbohydrates being quantitatively much less prominent in most fish than in mammals (Dabrowski and Guderley, 2002). Indeed the lipid (oil) content of fish can markedly exceed the protein content, reflecting the major role lipids and specifically their constituent fatty acids play as sources of metabolic energy in fish, for growth including reproduction and movement including migration (Tocher, 2003). Dietary lipid is also required to provide the necessary essential fatty acids (EFA) for formation of new cell membranes (Sargent et al., 1989). Thus lipid and fatty acids can either be incorporated into cell membranes and thus the flesh of the fish, or they can be oxidised to provide energy, or lipid can be deposited in adipose tissue as an energy store (Tocher, 2003). The more energy supplied by dietary lipid, the less dietary protein will be used for energy, and so more protein can be "spared" for synthesis of new tissue/flesh (Wilson, 1989; Bell, 1998). This phenomenon has been exploited in aquaculture and, in recent years, technical advances in extruded feed production have enabled the lipid or fat content of pelleted diets to increase greatly but, although protein sparing by dietary lipid is well documented, the limits to its effectiveness have not been accurately defined for any fish species (Company et al., 1999). Despite this, recent dietary formulations have tended to continue the upward trend in dietary lipid, particularly in the case of Atlantic salmon (Salmo salar) (Tocher, 2003). In many cases this has successfully increased weight gains, but several studies have shown that a potential and, perhaps, detrimental effect of high fat diets is the deposition of excess lipid in tissues, specifically flesh in the case of salmon (Sargent et al., 2002; Tocher, 2003). As well as dietary lipid levels, lipid deposition can be related to a number of factors including size, season and disease (Shearer, 1994; Sargent et al., 2002). Consequently, it is important to gain a clearer understanding of

the physiological mechanisms that control energy metabolism, and that determine lipid and fatty acid homeostasis in fish.

Conjugated linoleic acid (CLA) is a term used to describe positional and geometric isomers of linoleic acid (18:2n-6; LA), the two main naturally occurring isomers being cis-9, trans-11 and trans10 ,cis-12, that are known have physiological effects and health benefits including anticarcinogenic and immune enhancing properties in mammals (Belury, 2002). However, in addition, CLA also has several beneficial effects on lipid metabolism in mammals (DeLany and West, 2000), particularly in relation to body composition (Wang and Jones, 2004). Specifically, CLA decreased body fat and increased lean body mass in mice (Ohnuki et al., 2001; Terpstra et al., 2002), rats (Yamasaki et al., 2003) and pigs 
(Thiel-Cooper et al., 2001; Tischendorf et al., 2002). Decreased body fat has also been observed in human studies (Smedman and Vessby, 2001; Thom et al., 2001; Riserus et al., 2001) although the effect was much less than that observed with mice (Terpstra, 2004). CLA is also known to decrease the activity and gene expression of mammalian stearoyl CoA $\Delta 9$ desaturase (SCD) (Choi et al., 2001, 2002) and may also suppress $\Delta 6$ and $\Delta 5$ desaturase (Chuang et al., 2001a; Eder et al., 2002) and elongase (Chuang et al., 2001b). Further studies have suggested that CLA may enhance growth and feed efficiency in young rodents (Pariza et al., 2001) although this has not been consistently observed.

The aims of the present study were to determine the effects of CLA on lipid and fatty acid composition in Atlantic salmon. The overall objective being to test the hypotheses that CLA has beneficial effects in Atlantic salmon including growth enhancement, improved flesh quality through

decreased adiposity and lipid deposition thereby minimising detrimental effects of feeding high fat diets, and increased nutritional quality through increased levels of beneficial fatty acids including n3HUFA and CLA itself. In the trial described, salmon smolts were fed diets containing two levels of fish oil containing three levels of CLA for three months and the effects on growth performance, liver and flesh fat contents and fatty acid compositions determined.

\section{Materials and methods}

\subsection{Diets and Animals}

Photoperiod Atlantic salmon smolts $\left(\mathrm{S}^{1} / 2\right)$ were obtained from a commercial salmonid farm (Howietoun Fish Farm, Sauchieburn, Scotland) in late October and transported to the Stirling University, Institute of Aquaculture, Marine Environmental Research Laboratory, Machrihanish, Scotland. The fish were maintained in stock tanks for three weeks at ambient water temperature of around $10-11{ }^{\circ} \mathrm{C}$ to acclimatize during which time the fish were fed standard salmon diet, before being randomly distributed between eighteen indoor, round, conical tanks of $1.5 \mathrm{~m}^{3}$ volume $(1.72 \mathrm{~m}$ diameter). The initial stocking density was 100 fish of average fish weight $87.5 \pm 1.6 \mathrm{~g}$ per tank $\left(5.8 \mathrm{~kg} / \mathrm{m}^{3}\right)$. Water temperature was maintained at $12{ }^{\circ} \mathrm{C}\left( \pm 1{ }^{\circ} \mathrm{C}\right)$ throughout the trial, with a light regime of $12 \mathrm{~L}: 12 \mathrm{D}$. Six experimental diets were fed to triplicate tanks for 3 months, with feed supplied to appetite manually. The experimental diets were formulated to satisfy the nutritional requirements of salmonid fish (U.S. National Research Council, 1993), and were formulated and manufactured by BioMar A/S, Brande, Denmark. The trial had a $2 \times 3$ factorial design with CLA added at three concentrations to diets with 
two oil contents (low and high). Thus diets were produced with 0,1 and $2 \%$ CLA replacing standard Northern hemisphere fish oil in smolt feeds of containing either 18 or $34 \%$ total lipid. The diets were thus formulated to investigate also whether the effects of CLA, if any, were more dependent upon absolute content of CLA in the diet (as percentage of total diet) or the relative level of CLA to other fatty acids. Diets were formulated to be isonitrogenous and so protein content was constant between diets of different oil content (Table 1). Diets within the low or high oil groups were identical in formulation other than fatty acid composition with CLA (LUTA-CLA ${ }^{\mathrm{TM}}$ 60, containing 60\% CLA methyl esters as a 50:50 mixture of c9, t11 and t10, c12 isomers; BASF AG, Ludwigshafen, Germany) balanced by fish oil (capelin oil, Norsemeal Ltd., London, UK). The fatty acid compositions of the diets are presented in Table 2.

\subsection{Sampling protocols}

At the initiation and termination of the trial, all the fish in each tank were anaesthetised with benzocaine $(50 \mathrm{mg} / \mathrm{L})$, and bulk weighed. At the end of the trial, 24 fish per dietary treatment $(8 / \operatorname{tank})$ were individually weighed and sampled for compositional analyses, with 6 whole fish (2/tank) frozen immediately on dry ice for whole body compositional (proximate) analyses. The remaining sampled fish were eviscerated and used for biometric determinations (hepato-, and viscero-somatic indices) and for tissue lipid analyses. Flesh samples (Norwegian quality cut) and livers were taken from each fish, pooled in six samples of 3 fish each, and frozen immediately in liquid nitrogen (livers) or dry ice (flesh). All samples were subsequently stored at $-20{ }^{\circ} \mathrm{C}$ prior to analyses. Six fish per treatment (2/tank) were also collected after 1 and 2 months for tissue lipid analyses.

\subsection{Proximate analyses (whole body moisture, lipid, protein and ash determinations}

Moisture content of whole fish was determined after drying in an oven at $80{ }^{\circ} \mathrm{C}$ for a minimum of 72 h. The dried fish samples were then rigorously blended into a homogeneous crumble/meal and used for determination of whole body lipid, protein and ash contents. Lipid content in $1 \mathrm{~g}$ samples of dried fish crumb was determined using the Soxhlet method with extraction in petroleum ether at $120{ }^{\circ} \mathrm{C}$ (Avanti Soxtec 2050 Auto Extraction apparatus; Foss, Warrington, UK). Protein content (N x 6.25) was determined in the fish crumble using the automated Kjeldahl method (Tecator Kjeltec Auto 1030 Analyser; Foss, Warrington, UK). Ash contents were determined after heating portions of the fish crumble at $160{ }^{\circ} \mathrm{C}$ for $48 \mathrm{~h}$. 


\subsection{Lipid analyses}

Liver and skinned and deboned flesh samples, each consisting of three fish, were homogenised into pooled "pates". Total lipid was extracted from diets or $1 \mathrm{~g}$ portions of tissue pates by homogenising in 20 volumes of chloroform/methanol $(2: 1, \mathrm{v} / \mathrm{v})$ in an Ultra-Turrax tissue disrupter (Fisher Scientific, Loughborough, U.K.). Total lipid was prepared according to the method of Folch et al. (1957) and nonlipid impurities removed by washing with $0.88 \%(\mathrm{w} / \mathrm{v}) \mathrm{KCl}$. The weight of lipid was determined gravimetrically after evaporation of solvent and overnight desiccation in vacuo. Separation of lipid classes was performed by high-performance thin-layer chromatography (HPTLC). Approximately 10 $\mu \mathrm{g}$ of total lipid was applied as $2 \mathrm{~mm}$ streaks and the plate developed to two-thirds distance with methyl acetate/isopropanol/ chloroform/methanol/0.25\% aqueous $\mathrm{KCl}$ (25:25:25:10:9, by vol.). After desiccation, the plate was fully developed with isohexane/diethyl ether/acetic acid (85:15:1, by vol.). The lipid classes were visualised by charring at $160{ }^{\circ} \mathrm{C}$ for $15 \mathrm{~min}$ after spraying with $3 \%$ (w/v) aqueous cupric acetate containing $8 \%(\mathrm{v} / \mathrm{v})$ phosphoric acid and quantified by densitometry using a Camag 3 TLC Scanner (Camag, Muttenz, Switzerland) and winCATS software (Henderson and Tocher, 1992). The identities of individual lipid classes were confirmed by comparison with reference to the Rf values of authentic standards run alongside samples on HPTLC plates and developed in the above solvent systems.

Fatty acid methyl esters (FAME) from diets and tissue total lipid were prepared by acid-catalysed transesterification of total lipid according to the method of Christie (1982). Extraction and purification of FAME was performed as described by Tocher and Harvie (1988). FAME were separated and quantified by gas-liquid chromatography (Carlo Erba Vega 8160, Milan, Italy) using a 30m x $0.32 \mathrm{~mm}$ i.d. capillary column (CP Wax 52CB, Chrompak, London, U.K.) and on-column injection. Hydrogen was used as carrier gas and temperature programming was from $50^{\circ} \mathrm{C}$ to $150^{\circ} \mathrm{C}$ at $40^{\circ} \mathrm{C} \min ^{-1}$ and then to $230^{\circ} \mathrm{C}$ at $2.0^{\circ} \mathrm{C} \mathrm{min}^{-1}$. Individual methyl esters were identified by comparison with known standards and by reference to published data (Ackman, 1980; Tocher and Harvie, 1988). Data were collected and processed using the Chromcard for Windows (version 1.19) computer package (Thermoquest Italia S.p.A., Milan, Italy).

\subsection{Materials}


BHT was obtained from Sigma Chemical Co. (Poole, U.K.). HPTLC (10 cm x $10 \mathrm{~cm}$ x $0.15 \mathrm{~mm})$ and TLC (20 cm x $20 \mathrm{~cm}$ x $0.25 \mathrm{~mm}$ ) plates, precoated with silica gel 60 (without fluorescent indicator) were obtained from Merck (Darmstadt, Germany). All solvents were HPLC grade and were obtained from Fisher Scientific UK, Loughborough, England.

\subsection{Statistical analysis}

All data are presented as means \pm SD (n value as stated). Percentage data and data which were identified as non-homogeneous (Bartlett's test) were subjected to arcsine transformation before analysis. The effects of dietary CLA and oil content were determined by two-way analysis of variance (ANOVA) with Bonferroni post-tests to determine significance of differences due to CLA. Differences were regarded as significant when $\mathrm{P}<0.05$ (Zar, 1984).

\section{Results}

\subsection{Diet composition}

Inclusion of CLA in the low oil diets resulted in levels of total CLA of $5.9 \%$ and $9.5 \%$ of total fatty acids at the 1 and 2\% inclusion levels, respectively (Table 2). Obviously, in the high oil diets, inclusion of CLA at 1 and 2\% resulted in lower levels of total CLA, at 3.3\% and 5.8\% of total fatty acids, respectively. Note that the levels of CLA in relative terms were identical in the L1 and H2 diets with an overall rank order for CLA content of $\mathrm{L} 2>\mathrm{L} 1=\mathrm{H} 2>\mathrm{H} 1>\mathrm{LO} / \mathrm{H} 0$.

\subsection{Growth and biometry}

There were no effects of diet on growth parameters, with no significant effects of CLA or oil content on final weights, specific growth rate (SGR) or feed efficiency as measured by feed conversion ratio (FCR) (Table 3). Viscero-somatic (VSI) and hepato-somatic (HSI) indices were both significantly increased in fish fed the diets with the high oil content, but dietary CLA had no affect on these parameters (Table 3).

\subsection{Whole body proximate compositions}


The composition of whole fish was significantly affected by the oil content of the diet with lipid content significantly increased and protein, moisture, ash and protein:lipid ratio all significantly reduced in fish fed the high oil diets (Table 4). Dietary CLA had no significant effects on proximate composition of the whole fish.

\subsection{Lipid contents and class compositions of liver and flesh}

Liver and flesh (muscle) lipid contents were significantly increased in fish fed the diets containing the higher oil content (Table 5). The increased lipid contents in fish fed the high oil diets were reflected in increased proportions of triacylglycerol (TAG) and total neutral lipids in both the liver (Table 6) and flesh (Table 7). Dietary CLA also had an effect on the lipid content of liver and flesh with increasing CLA leading to increased lipid content (Table 5). This effect was more pronounced in fish fed the high oil diets and was significant in the case of flesh although it was just short of statistical significance in the liver (Table 5). The increased lipid content in the liver in response to dietary CLA was also reflected in increased proportions of TAG and total neutral lipids particularly in the high oil diets (Table 6). Similarly, increased lipid contents in the flesh in response to dietary CLA were reflected in increased proportions of TAG and total neutral lipids (Table 7). The effects of CLA and oil content on liver and flesh lipid contents and class compositions as described above were statistically significant except for TAG levels in the liver (Table 8).

\subsection{Fatty acid compositions of liver and flesh}

The fatty acid compositions of total lipid from liver (Table 9) and flesh (Table 10) reflected the fatty acid composition of the diets. Dietary CLA resulted in the deposition of CLA in both tissues with the rank order for total CLA in both liver and flesh being L2 > H2 > L1 > H1 > L0/H0 (Tables 9 and 10). Accumulation of CLA was 2-fold higher in the flesh, with total CLA in fish fed the L2 diet reaching $3.4 \%$ in the liver (Table 9), and 6.9\% in the flesh (Table 10). CLA deposition in the liver was not at the expense of any one particular fatty acid but tended to be spread across several saturated and monounsaturated fatty acids (Tables 8 and 9). In contrast, in the flesh, CLA deposition appeared to be primarily at the expense of 20:5n-3 and 22:6n-3 rather than saturated and monounsaturated fatty acids (Tables 8 and 10). It was noteworthy that dietary CLA had no significant effect on the proportions of n-6 fatty acids 18:2n-6 or 20:4n-6 in either liver or flesh (Tables 8-10). Oil content also had an effect 
on tissue fatty acid compositions with most fatty acids being significantly affected, with fatty acids derived from the plant (meal) sources, such as 18:0, 18:1n-9 and 18:2n-6, being reduced and generally all the other fatty acids being increased in liver and flesh of fish fed the high oil diets (Tables 8-10).

\section{Discussion}

The primary aim of the present trial was to determine if dietary CLA had any important effects on lipid metabolism and growth parameters in Atlantic salmon. In a recent study, no effect of dietary CLA on growth rate or proximate composition was observed in Atlantic salmon fry fed diets containing up to 2\% CLA (Berge et al., 2004). Similarly, no effects on weight gain or feed efficiency were noted in juvenile yellow perch (Perca flavescens) or catfish (Ictalurus punctatus) fed diets containing up to 1\% CLA (Twibell et al., 2001; Twibell and Wilson, 2003). Higher levels of dietary CLA, up to 5\% of diet, also had no effect on growth or feed efficiency in juvenile tilapia (Oreochromis niloticus) (Yasmin et al., 2004). An earlier trial reported that CLA at $0.5 \%$ and $0.75 \%$ had no effect on growth but at $1 \%$ of the diet decreased growth in hybrid striped bass (Morone saxatilis x M. chrysops), although there was a trend for increased feed efficiency with increased dietary CLA (Twibell et al., 2000). Most of these trials used diets with lipid contents in the range 6-12\%, which is perhaps too low to fully investigate the effects of CLA, if its mechanism of action is through modulation of lipid metabolism and homeostasis (refs). However, the trial on salmon fry used diets containing 24\% lipid (Berge et al., 2004), and in the trial described here with salmon smolts, lipid levels of up to $34 \%$ were used, and still no positive effects on growth were obtained. Overall, therefore the data suggest that dietary CLA does not have any beneficial effects on growth performance in fish, including salmon that can tolerate high levels of lipid in their diet.

Dietary CLA has some beneficial effects on body composition in mammals, with decreased body fat and increased lean body mass having been shown in mice, rats and pigs (Ohnuki et al., 2001; ThielCooper et al., 2001; Terpstra et al., 2002; Tischendorf et al., 2002; Yamasaki et al., 2003). CLA also decreased whole body TAG accumulation in hamsters (Bouthegourd et al., 2002) and reduced liver TAG levels in rats (Rahman et al., 2002). In contrast, similar effects have rarely been observed with fish. No effect on whole body proximate composition was observed with salmon smolts in the present trial, or in a previous trial with salmon fry (Berge et al., 2004). Dietary CLA had no significant effect on carcass lipid, intraperitoneal fat or liver lipid content in catfish (Twibell and Wilson, 2003), or on tissue lipid contents in tilapia (Yasmin et al., 2004). However, intraperitoneal fat and liver lipid content were decreased by dietary CLA in striped bass although, perhaps surprisingly, HSI was increased 
(Twibell et al., 2000), as it was in yellow perch (Twibell et al., 2001) and in tilapia (Yasmin et al., 2004). HSI was not increased in the present trial by dietary CLA, although it was increased in fish fed the high oil diets. The increased HSI was associated with increased lipid and TAG content in the liver, whereas in the studies on yellow perch and tilapia, increased HSI was not associated with increased lipid content and, indeed, liver lipid content was reduced by CLA in striped bass (Twibell et al., 2001; Yasmin et al., 2004).

In 3T3-L1 adipocytes, CLA suppressed TAG accumulation (Evans et al., 2000) and the t10,c12 isomer increased fatty acid oxidation (Evans et al., 2002). CLA inhibited fatty acid synthetase activity in rat liver. (Oku et al., 2003), and the t10,c12 isomer attenuated lipogenesis in human AT cells (Brown et al., 2001). Therefore, CLA can affect lipid accumulation both by decreasing synthesis and increasing oxidation. However, to date only gross effects have been measured in fish and the biochemical pathways have not been directly studied. This would also be an interesting area for further studies.

In the present trial we also aimed to determine if absolute content of CLA in the diet or the level of CLA relative to other fatty acids in the diets was more important in eliciting effects, and the diets were specifically formulated to this end. The appropriate formulations were largely achieved and the diets provided a graded amount of CLA relative to total fatty acids with diets L1 and H2 supplying around the same relative amount of CLA but at two levels of dietary inclusion, $1 \%$ and $2 \%$. The few effects made it difficult to be conclusive on the relative importance of absolute or relative amount of dietary CLA. However, the effects of dietary CLA were generally more pronounced in salmon fed the high oil diets suggesting that oil content in the diet was important in determining the effects of CLA. The effects of dietary oil content itself were obvious and entirely predictable and consistent with higher dietary oil leading to higher deposition of fat in the tissues (Sargent et al., 2002; Tocher 2003).

Taking all the studies together, it is clear that dietary CLA has effects on lipid homeostasis in fish. However, the effects are not consistent and may vary with species, dependent upon the pattern of lipid metabolism which itself varies the species (Tocher 2003). In addition, patterns of lipid metabolism also vary with developmental stage of the fish ands so this may also be important (Tocher 2003. All the previous trials used juvenile fish (Twibell et al., 2000,2001; Twibell and Wilson, 2003; Berge et al., 2004; Yasmin et al., 2004), and the present trial used new smolts, but older, larger salmon that are very actively accumulating lipid would be interesting to study. However, the results obtained may also be dependent upon other dietary factors such as lipid content and oil composition, relative level of dietary CLA and isomer mix, and duration of the experiment. Levels of oil used in the trials of CLA in fish have varied between 5 and $12 \%$, or up to $24 \%$ and $34 \%$ in salmon, generally as fish oil, although the 
precise fish oil varied, and two trials also used diets including a mix of fish oil and vegetable oils such as corn oil and soybean oil (Twibell et al., 2000,2001; Twibell and Wilson, 2003; Berge et al., 2004; Yasmin et al., 2004). The levels of CLA varied between 0.5 and 5\%, and although all were basically a 1:1 mix of the two main isomers (c9,t11 and t10,c12), the precise chemical form (free fatty acid, methyl esters or triglyceride) were not defined in most of the trials.

In mammals, CLA is also known to decrease the activity and gene expression of SCD and may also suppress $\Delta 6$ and $\Delta 5$ desaturases, and elongase (Choi et al., 2001, 2002; Chuang et al., 2001a,b; Eder et al., 2002). Dietary CLA increased saturated fatty acids and decreasing 18:1 and $\mathrm{C}_{18}$ PUFA in pig muscle and fat (Ramsay et al., 2001), and in chickens it decreased 22:6n-3 in all tissues (Yang et al., 2003), and increased saturates and decreased monoenes and PUFA in eggs (Szyczyk and Pisulewski 2003). The tissue fatty acid composition data in the present study indicated that dietary CLA might have some similar effects in salmon. Thus, there was an indication that SCD in liver was reduced as evidenced by increased 18:0 and decreased 18:1n-9, and a similar effect was observed previously in salmon fry fed CLA (Berge et al., 2004). In the present study, it was noteworthy that deposition of CLA in flesh was at the expense of n-3HUFA whereas in liver it was at the expense of saturated and monounsaturated fatty acids. Unfortunately, the benefits of CLA-fed fish would be greater if this was the other way around and CLA replaced saturated and monounsaturated fatty acids in the flesh. Dietary CLA has had rather diverse effects on tissue fatty acid compositions in fish. Lower 16:1n-7 was reported in striped bass, and lower monoenes were reported in liver and muscle of yellow perch and in tilapia tissues (Twibell et al., 2000,2001; Yasmin et al., 2004), In striped bass, CLA increased PUFA including 20:5n-3, 22:6n-3 and 18:2n-6 in liver but decreased in muscle (Twibell et al., 2000). Total n-3PUFA, especially 22:6n-3, were increased in salmon fry fed CLA (Berge et al., 2004), but PUFA were reduced in both liver and muscle in yellow perch (Twibell et al., 2001). CLA fed to tilapia lowered 18:2n-6 but had no effect on 20:4n-6 (Yasmin et al., 2004).

In summary, CLA had no effect on growth parameters, but there was a clear trend of increased total lipid and TAG contents in both liver and flesh in fish fed CLA, particularly in fish fed the high oil diets. CLA was incorporated into tissue lipids, with levels in flesh being 2-fold higher than in liver, but importantly, incorporation in liver was at the expense of saturated and monounsaturated fatty acids whereas in flesh it was at the expense of n-3HUFA. In conclusion however, the results of the present study generally do not support hypotheses that we set out to test. Thus CLA had few beneficial effects in salmon smolts and did not enhance growth parameters or improve flesh quality through decreased 
adiposity or lipid deposition. However, salmon fed CLA could be beneficial in the human diet through provision of CLA with minimal effect on n-3HUFA levels.

\section{Acknowledgements}

This work and SRK was supported by a Biotechnology and Biological Science Research Council (BBSRC) CASE studentship award (BioMar Ltd., Grangemouth, Scotland).

\section{References}

Ackman, R.G., 1980. Fish lipids, part 1. In: Connell, J.J. (Ed.), Advances in Fish Science and Technology. Fishing News, Farnham, pp. 87-103.

Bell, J.G., 1998. Current aspects of lipid nutrition in fish farming. In: Black, K.D. and Pickering, A.D. (Eds.), Biology of Farmed Fish. Sheffield Academic, Sheffield, pp. 114-145.

Belury, M.A. 2002. Dietary conjugated linoleic acid in health: physiological effects and mechanisms of action. Annu. Rev. Nutr. 22, 505-531.

Berge, G.M., Ruyter, B., Asgard, T. 2004. Conjugated linoleic acid in diets for juvenile Atlantic salmon (Salmo salar); effects on fish performance, proximate composition, fatty acid and mineral content. Aquaculture 237, 365-380.

Bouthegourd, J.C., Even, P.C., Gripois, D., Toffon, B., Blouquit, M.F., Roseau, S., Lutton, C., Tome, D., Martin, J.C., 2002. A CLA mixture prevents body triglyceride accumulation without affecting energy expenditure in Syrian hamsters. J. Nutr. 132, 2682-2689.

Brown, J.M., Halvorsen, Y.D., Lea-Currie, Y.R., Geigerman, C., McIntosh, M., 2001. Trans-10,cis-12, but not cis-9, trans-11, conjugated linoleic acid attenuates lipogenesis in primary cultures of stromal vascular cells from human adipose tissue. J. Nutr. 131, 2316-2321.

Choi, Y., Park, Y., Pariza, M.W., Ntambi, J,M., 2001. Regulation of stearoyl-CoA desaturase activity by the trans-10,cis-12 isomer of conjugated linoleic acid in HepG2 cells. Biochem Biophy. Res. Commun. 284, 689-693.

Choi, Y., Park, Y., Storkson, J.M., Pariza, M.W., Ntambi, J,M., 2002. Inhibition of stearoyl-CoA desaturase activity by the cis-9,trans-11 isomer and the trans-10,cis-12 isomer of conjugated linoleic acid in MDA-MB-231 and MCF-7 human breast cancer cells. Biochem Biophy. Res. Commun. 294, 785-790.

Christie, W.W., 1982. Lipid Analysis, 2nd edition. Pergamon, Oxford, pp. 207. 
Chuang, L.T., Leonard, A.E., Liu, J.W., Mukerji, P., Bray, T.M., Huang, Y.S., 2001b. Inhibitory effect of conjugated linoleic acid on linoleic acid elongation in transformed yeast with human elongase. Lipids 36, 1099-1103.

Chuang, L.T., Thurmond, J.M., Liu, J.W., Kirchner, S.J., Mukerji, P., Bray, T.M., Huang, Y.S., 2001 a. Effect of conjugated linoleic acid on fungal $\Delta 6$-desaturase activity in a transformed yeast system. Lipids 36, 139-143.

Company, R., Calduch-Giner, J.A., Kaushik, S., Perez-Sanchez, S.J., 1999. Growth performance and adiposity in gilthead sea bream (Sparus aurata): risks and benefits of high energy diets. Aquaculture $171,279-292$.

Dabrowski, K., Guderley, H., 2002. Intermediary metabolism. In: Halver, J.E., Hardy, R.W. (Eds.), Fish Nutrition, (Third edition) Academic, San Diego, pp. 309-365.

Delany, J.P., West, D.B., 2000. Changes in body composition with conjugated linoleic acid. J. Am. Coll. Nutr. 19, 487S-493S.

Eder, K., Slomma, N., Becker, K., 2002. Trans-10,cis-12 conjugated linoleic acid suppresses the desaturation of linoleic and $\alpha$-linolenic acids in HepG2 cells. J. Nutr. 132, 1115-1121.

Evans, M., Geigerman, C., Cook, J., Curtis, L., Kuebler, B., McIntosh, M., 2000. Conjugated linoleic acid suppresses triglyceride accumulation and induces apoptosis in 3T3-L1 preadipocytes. Lipids 35, 899-910.

Evans, M., Lin, X., Odle, J., McIntosh, M., 2002. Trans-10,cis-12 conjugated linoleic acid increases fatty acid oxidation in 3T3-L1 preadipocytes. J. Nutr. 132, 450-455.

Folch, J., Lees, M., Sloane-Stanley, G.H., 1957. A simple method for the isolation and purification of total lipids from animal tissues. J. Biol. Chem. 226, 497-509.

Henderson, R. J., Tocher, D. R., 1992. Thin-layer chromatography. In: Hamilton, R. J., Hamilton, S. (Eds.), Lipid Analysis : A Practical Approach. Oxford University, Oxford, pp. 65-111.

Ohnuki, K., Haramizu, S., Ishihara, K., Fushiki, T., 2001. Increased energy metabolism and suppressed body fat accumulation in mice by a low concentration of conjugated linoleic acid. Biosci. Biotechnol. Biochem. 65, 2200-2204.

Oku, H., Wongtangtintharn, S., Iwasaki, H., Toda, T., 2003. Conjugated linoleic acid (CLA) inhibits fatty acid synthetase activity in vitro. Biosci. Biotechnol. Biochem. 67, 1584-1586.

Pariza, M.W., Park, Y., Cook, M.E., 2001. The biologically active isomers of conjugated linoleic acid. Prog. Lipid Res. 40, 283-298. 
Rahman, S.M., Huda, M.N., Uddin, M.N., Akhteruzzaman, S., 2002. Short-term administration of conjugated linoleic acid reduces liver triglyceride concentration and phosphatidate phosphohydrolase activity in OLETF rats. J. Biochem. Mol. Biol. 35, 494-497.

Ramsay, T.G., Evock-Clover, C.M., Steele, N.C., Azain, M.J., 2001. Dietary conjugated linoleic acid alters fatty acid composition of pig skeletal muscle and fat. J. Anim. Sci. 79, 2152-2161.

Riserus, U., Berglund, L., Vessby, B., 2001. Conjugated linoleic acid (CLA) reduced abdominal adipose tissue in obese middle-aged men with signs of the metabolic syndrome: a randomised controlled trial. Internat. J. Obesity Related Metabolic Disorders 25, 1129-1135.

Sargent, J. R., Henderson, R. J., Tocher, D. R., 1989. The lipids. In: Halver, J. E. (Ed.), Fish Nutrition (Second edition), Academic, San Diego, pp. 154-219.

Sargent, J.R., Tocher, D.R. and Bell, J.G. 2002. The lipids In: Halver, J.E., Hardy, R.W. (Eds.), Fish Nutrition (Third edition), Academic, San Diego, pp. 181-257.

Shearer, K.D. 1994. Factors affecting the proximate composition of cultured fishes with emphasis on salmonids. Aquaculture 119, 63-88.

Smedman, A., Vessby, B., 2001. Conjugated linoleic acid supplementation in humans - metabolic effects. Lipids 36, 773-781.

Szymczyk, B., Pisulewski, P.M., 2003. Effects of dietary conjugateds linoleic acid on fatty acid composition and cholesterol content of hen egg yolks. Br. J. Nutr. 90, 93-99.

Terpstra, A.H., 2004. Effect of conjugated linoleic acid on body composition and plasma lipids in humans: an overview of the literature. Am. J. Clin. Nutr. 79, 352-361.

Terpstra, A.H., Beynen, A.C., Everts, H., Kocsis, S., Katan, M.B., Zock, P.L., 2002. The decrease in body fat in mice fed conjugated linoleic acid is due to increases in energy expenditure and energy loss in the excreta. J. Nutr. 132, 940-945.

Thiel-Cooper, R.L., Parrish, F.C., Sparks, J.C., Weigand, B.R., Ewan, R.C., 2001. Conjugated linoleic acid changes swine performance and carcass composition. J. Anim. Sci. 79, 1821-1828.

Thom, E., Wadstein, J., Gudmundsen, O., 2001. Conjugated linoleic acid reduces body fat in healthy exercising humans. J. Internat. Med. Res. 29, 392-396.

Tischendorf, F., Schone, F., Kirchheim, U., Jahreis, G., 2002. Influence of a conjugated linoleic acid mixture on growth, organ weights, carcass traits and meat quality in growing pigs. J. Anim. Physiol. Anim. Nutr. 86, 117-128.

Tocher, D.R., 2003. Metabolism and functions of lipids and fatty acids in teleost fish. Rev. Fish. Sci. $11,107-184$. 
Tocher, D.R., Harvie, D.G., 1988. Fatty acid compositions of the major phosphoglycerides from fish neural tissues : (n-3) and (n-6) polyunsaturated fatty acids in rainbow trout (Salmo gairdneri, L.) and cod (Gadus morhua) brains and retinas. Fish Physiol. Biochem. 5, 229-239.

Twibell, R.G., Wilson, R.P., 2003. Effects of conjugated linoleic acids and total dietary lipid concentrations on growth responses of juvenile channel catfish, Ictalurus punctatus. Aquaculture 221, 621-628.

Twibell, R.G., Watkins, B.A., Brown, P.B., 2001. Dietary conjugated linoleic acids and lipid source alter fatty acid composition of juvenile yellow perch, Perca flavescens. J. Nutr. 131, 2322-2328.

Twibell, R.G., Watkins, B.A., Rogers, L., Brown, P.B., 2000. Effects of dietary conjugated linoleic acids on hepatic and muscle lipids in hybrid striped bass. Lipids 35, 155-161.

U.S. National Research Council, 1993. Nutrient requirements of fish. National Academy, Washington. Wang, Y., Jones, P.J. 2004. Dietary conjugated linoleic acid and body composition. Am. J. Clin. Nutr. 79, 1153S-1158S.

Wilson, R. P. (1989). Amino acids and proteins. In: Halver, J. E. (Ed.), Fish Nutrition (Second edition), Academic, San Diego, pp. 111-151.

Yamasaki, M., Ikeda, A., Oji, M., Tanaka, Y., Hirao, A., Kasai, M., Iwata, T., Tachibana, H., Yamada, K., 2003. Modulation of body fat, and serum leptin levels by dietary conjugated linoleic acid in Sprague-Dawley rats fed various fat-level diets. Nutrition 19, 30-35.

Yang, L., Huang, Y., Wang, H.Q., Chen, Z.Y., 2003. Isomeric distribution of conjugated linoleic acid (CLA) in the tissues of layer hens fed a CLA diet. J. Agricultural Fd. Chem. 51, 5654-5660.

Yasmin, A., Takeuchi, T., Hayashi, M., Hirota, T., Ishizuka, W. and Ishida, S., 2004. Effect of conjugated linoleic and docosahexaenoic acids on growth of juvenile tilapia Oreochromis niloticus. Fisheries Sci. 70, 473-481.

Zar, J.H., 1984. Biostatistical Analysis, 2nd Edition. Prentice-Hall, Englewood Cliffs. 
Table 1. Formulations (percentage of dry ingredients) and proximate compositions (percentage of total diet) of experimental diets

\begin{tabular}{lcccccc}
\hline & L0 & L1 & L2 & H0 & H1 & H2 \\
\hline Fishmeal & 44 & 44 & 44 & 50 & 50 & 50 \\
Sunflower meal & 15 & 15 & 15 & 4 & 4 & 4 \\
Corn Gluten & 8 & 8 & 8 & 8 & 8 & 8 \\
Legume seeds & 9 & 9 & 9 & 9 & 9 & 9 \\
Cereal grains & 10 & 10 & 10 & 0 & 0 & 0 \\
Micronutrients & 3 & 3 & 3 & 2 & 2 & 2 \\
Fish oil & 11 & 9.3 & 7.6 & 27 & 25.3 & 23.6 \\
CLA & 0 & 1.7 & 8.4 & 0 & $4.2 \pm 0.4$ & $4.4 \pm 0.1$ \\
Moisture & $8.0 \pm 0.3$ & $8.7 \pm 0.1$ & $8.9 \pm 0.1$ & $3.1 \pm 0.1$ & 4.2 & $32.6 \pm 1.6$ \\
Lipid & $18.2 \pm 0.3$ & $17.4 \pm 0.1$ & $16.4 \pm 0.5$ & $33.2 \pm 0.6$ & $32.4 \pm 1.2$ & $47.1 \pm 1.3$ \\
Protein & $44.8 \pm 0.1$ & $44.8 \pm 0.2$ & $45.8 \pm 0.5$ & $47.0 \pm 0.3$ & $47.0 \pm 0.3$ & $8.0 \pm 0.2$ \\
Ash & $7.8 \pm 0.1$ & $7.8 \pm 0.1$ & $7.9 \pm 0.1$ & $8.2 \pm 0.1$ & $8.1 \pm 0.0$ & $8.0 \pm$ \\
\hline
\end{tabular}

Results for proximate compositions are means \pm S.D. ( $n=3)$. Micronutrients, incl. essential amino acids (methionine and lysine), vitamins, minerals and astaxanthin (Carophyll pink ${ }^{\circledR}$ ), Biomar A/S, Brande, Denmark. $\mathrm{H} 0, \mathrm{H} 1$ and $\mathrm{H} 2$, diets containing fish oil at $34 \%$ and supplemented with 0,1 and $2 \%$ CLA;

L0,L1 and L2, diets containing fish oil at $17 \%$ and supplemented with 0,1 and $2 \%$ CLA. 
Table 2. Fatty acid composition (percentage of weight) of experimental diets containing conjugated linoleic acid (CLA) fed to Atlantic salmon (Salmo salar).

\begin{tabular}{|c|c|c|c|c|c|c|}
\hline & L0 & L1 & L2 & $\mathrm{HO}$ & $\mathrm{H} 1$ & $\mathrm{H} 2$ \\
\hline $14: 0$ & $5.6 \pm 0.2$ & $4.7 \pm 0.1$ & $4.3 \pm 0.3$ & $6.8 \pm 0.3$ & $6.0 \pm 0.2$ & $5.8 \pm 0.1$ \\
\hline $16: 0$ & $19.6 \pm 0.5$ & $18.1 \pm 0.7$ & $18.2 \pm 0.7$ & $19.9 \pm 0.2$ & $19.2 \pm 0.2$ & $19.2 \pm 0.3$ \\
\hline 18:0 & $4.5 \pm 0.2$ & $4.5 \pm 0.1$ & $5.0 \pm 0.4$ & $4.3 \pm 0.0$ & $4.4 \pm 0.1$ & $4.6 \pm 0.1$ \\
\hline Total saturated ${ }^{1}$ & $30.7 \pm 1.0$ & $28.6 \pm 1.1$ & $28.9 \pm 1.4$ & $31.9 \pm 0.4$ & $30.6 \pm 0.7$ & $31.0 \pm 0.8$ \\
\hline $16: 1 \mathrm{n}-7^{2}$ & $6.7 \pm 0.1$ & $5.7 \pm 0.2$ & $5.3 \pm 3.5$ & $7.5 \pm 0.1$ & $6.9 \pm 0.1$ & $6.7 \pm 0.1$ \\
\hline $18: 1 n-9$ & $13.4 \pm 0.2$ & $15.1 \pm 0.2$ & $17.7 \pm 0.6$ & $12.0 \pm 0.2$ & $13.1 \pm 0.1$ & $14.2 \pm 0.0$ \\
\hline $18: 1 n-7$ & $2.9 \pm 0.1$ & $2.6 \pm 0.0$ & $2.5 \pm 0.1$ & $3.0 \pm 0.1$ & $2.9 \pm 0.1$ & $2.9 \pm 0.1$ \\
\hline $20: 1 n-9^{3}$ & $3.0 \pm 0.0$ & $2.9 \pm 0.3$ & $2.5 \pm 0.1$ & $3.2 \pm 0.1$ & $2.8 \pm 0.0$ & $2.9 \pm 0.2$ \\
\hline $22: 1 \mathrm{n}-11^{4}$ & $3.4 \pm 0.0$ & $3.1 \pm 0.0$ & $2.4 \pm 0.1$ & $3.2 \pm 0.0$ & $2.9 \pm 0.0$ & $2.7 \pm 0.0$ \\
\hline $24: 1 n-9$ & $0.7 \pm 0.1$ & $0.7 \pm 0.0$ & $0.6 \pm 0.0$ & $0.8 \pm 0.0$ & $0.7 \pm 0.0$ & $0.7 \pm 0.0$ \\
\hline Total monoenes & $30.1 \pm 0.7$ & $30.0 \pm 0.7$ & $31.0 \pm 0.9$ & $29.8 \pm 0.6$ & $29.3 \pm 0.4$ & $30.2 \pm 0.5$ \\
\hline $18: 2 n-6$ & $6.4 \pm 0.2$ & $6.6 \pm 0.1$ & $6.8 \pm 0.2$ & $3.1 \pm 0.1$ & $3.3 \pm 0.0$ & $3.2 \pm 0.0$ \\
\hline $20: 4 n-6$ & $0.9 \pm 0.0$ & $0.8 \pm 0.0$ & $0.7 \pm 0.0$ & $1.0 \pm 0.1$ & $0.9 \pm 0.0$ & $0.8 \pm 0.0$ \\
\hline CLA $(9 \mathrm{c}, 11 \mathrm{t})$ & $0.0 \pm 0.0$ & $2.9 \pm 0.5$ & $4.8 \pm 1.6$ & $0.0 \pm 0.0$ & $1.6 \pm 0.2$ & $2.9 \pm 0.7$ \\
\hline CLA $(10 t, 12 c)$ & $0.0 \pm 0.0$ & $3.0 \pm 0.4$ & $4.6 \pm 1.7$ & $0.0 \pm 0.0$ & $1.7 \pm 0.4$ & $2.9 \pm 0.8$ \\
\hline Total n-6 PUFA ${ }^{5}$ & $8.4 \pm 0.1$ & $14.1 \pm 1.0$ & $17.6 \pm 3.0$ & $5.1 \pm 0.1$ & $8.3 \pm 0.7$ & $10.6 \pm 1.5$ \\
\hline $18: 3 n-3$ & $1.2 \pm 0.0$ & $1.1 \pm 0.0$ & $1.0 \pm 0.0$ & $1.2 \pm 0.0$ & $1.2 \pm 0.0$ & $1.1 \pm 0.0$ \\
\hline $18: 4 n-3$ & $2.5 \pm 0.1$ & $2.1 \pm 0.0$ & $1.8 \pm 0.0$ & $2.7 \pm 0.0$ & $2.6 \pm 0.0$ & $2.3 \pm 0.0$ \\
\hline $20: 4 n-3$ & $0.7 \pm 0.0$ & $0.6 \pm 0.0$ & $0.5 \pm 0.0$ & $0.8 \pm 0.0$ & $0.8 \pm 0.0$ & $0.7 \pm 0.0$ \\
\hline $20: 5 n-3$ & $11.8 \pm 0.7$ & $10.2 \pm 0.2$ & $8.4 \pm 0.5$ & $13.6 \pm 0.1$ & $13.0 \pm 0.1$ & $11.5 \pm 0.1$ \\
\hline $22: 5 n-3$ & $1.8 \pm 0.1$ & $1.6 \pm 0.0$ & $1.3 \pm 0.1$ & $2.0 \pm 0.0$ & $1.9 \pm 0.0$ & $1.7 \pm 0.0$ \\
\hline $22: 6 n-3$ & $12.7 \pm 0.9$ & $11.5 \pm 0.5$ & $9.5 \pm 0.1$ & $12.9 \pm 0.0$ & $12.4 \pm 0.2$ & $10.9 \pm 0.1$ \\
\hline Total n-3 PUFA ${ }^{6}$ & $30.8 \pm 1.8$ & $27.3 \pm 0.8$ & $22.6 \pm 0.7$ & $33.2 \pm 0.3$ & $31.8 \pm 0.4$ & $28.2 \pm 0.2$ \\
\hline Total PUFA & $39.2 \pm 1.7$ & $41.5 \pm 1.8$ & $40.2 \pm 2.4$ & $38.3 \pm 0.2$ & $40.13 \pm 1$ & $38.8 \pm 1.3$ \\
\hline
\end{tabular}

Values are means \pm SD of 3 samples. ${ }^{1}$, contains 15:0, 20:0 and 22:0, present in some samples at up to 0.6\%;

${ }^{2}$, contains n-9 isomer; ${ }^{3}$, contains n-7 isomer; ${ }^{4}$, contains n-9 isomer; ${ }^{5}$, totals include 18:3n-6, 20:2n-6 and 22:5n-6 present in some samples at up to $0.4 \% ;^{6}$, contains $20: 3 \mathrm{n}-3$ present at up to $0.2 \%$. $\mathrm{H} 0, \mathrm{H} 1$ and $\mathrm{H} 2$, diets containing fish oil at 34\% and supplemented with 0,1 and 2\% CLA; L0,L1 and L2, diets containing fish oil at 17\% and supplemented with 0,1 and $2 \%$ CLA. 
Table 3. Growth and biometric parameters for Atlantic salmon (Salmo salar) fed the experimental diets for three months

\begin{tabular}{|c|c|c|c|c|c|c|c|c|c|}
\hline & \multirow[b]{2}{*}{ L0 } & \multirow[b]{2}{*}{ L1 } & \multirow[b]{2}{*}{$\mathrm{L} 2$} & \multirow[b]{2}{*}{$\mathrm{HO}$} & \multirow[b]{2}{*}{$\mathrm{H} 1$} & \multirow[b]{2}{*}{$\mathrm{H} 2$} & \multicolumn{3}{|c|}{ ANOVA } \\
\hline & & & & & & & CLA & Oil & Interact. \\
\hline Initial weight (g) & $87.8 \pm 1.5$ & $87.4 \pm 0.5$ & $87.9 \pm 2.2$ & $85.5 \pm 1.5$ & $89.3 \pm 0.9$ & $86.9 \pm 0.6$ & 0.1301 & 0.4740 & 0.0506 \\
\hline Final weight (g) & $203.2 \pm 7.1$ & $199.7 \pm 1.8$ & $195.1 \pm 12.3$ & $196.1 \pm 4.7$ & $201.0 \pm 10.1$ & $199.5 \pm 1.8$ & 0.7631 & 0.8964 & 0.4108 \\
\hline SGR & $1.02 \pm 0.1$ & $1.01 \pm 0.01$ & $0.97 \pm 0.05$ & $1.01 \pm 0.05$ & $0.99 \pm 0.05$ & $1.01 \pm 0.02$ & 0.6236 & 0.8749 & 0.4712 \\
\hline FCR & $1.24 \pm 0.1$ & $1.26 \pm 0.03$ & $1.32 \pm 0.13$ & $1.27 \pm 0.07$ & $1.29 \pm 0.10$ & $1.28 \pm 0.03$ & 0.6547 & 0.8681 & 0.7100 \\
\hline VSI & $9.20 \pm 0.61$ & $9.2 \pm 0.80$ & $9.42 \pm 0.43$ & $10.87 \pm 0.33$ & $10.66 \pm 0.52$ & $10.63 \pm 0.48$ & 0.9356 & 0.0001 & 0.7722 \\
\hline HSI & $1.09 \pm 0.09$ & $1.12 \pm 0.09$ & $1.11 \pm 0.06$ & $1.13 \pm 0.05$ & $1.20 \pm 0.03$ & $1.20 \pm 0.02$ & 0.3543 & 0.0372 & 0.7742 \\
\hline
\end{tabular}

Data are presented as means $\pm \mathrm{SD}(\mathrm{n}=3)$. CLA, conjugated linoleic acid; FCR, feed conversion ratio $=$ feed consumed $(\mathrm{kg}) / \mathrm{weight}$ gain $(\mathrm{kg})$;

HSI, Hepato-somatic index $=100 \mathrm{x}$ liver weight $\mathrm{x}$ body weight ${ }^{-1}$; SGR, specific growth rate $(\% /$ day $)=100 \mathrm{x}$ [(Final Weight / Initial Weight $) /$ Days $\left.{ }^{-1}\right]$;

VSI, Viscero-somatic index $=100 \mathrm{x}$ viscera weight $\mathrm{x}$ body weight ${ }^{-1 ;} \mathrm{L}$, L1 and L2, low lipid diets with 0, 1 and 2\% CLA; H0, H1 and H2, high lipid dis with 0,1 and $2 \%$ CLA. Significance (P values) of effects of CLA, oil content and their interaction were determined by two-way ANOVA as described in the Materials and Methods. 
Table 4. Proximate composition of whole Atlantic salmon (Salmo salar )

\begin{tabular}{lccccc}
\hline Diet & Moisture & Protein & Lipid & Ash & P:L ratio \\
\hline L0 & $69.8 \pm 1.1$ & $61.2 \pm 2.0$ & $29.7 \pm 3.1$ & $7.3 \pm 0.6$ & $2.06 \pm 0.20$ \\
L1 & $70.0 \pm 0.6$ & $62.1 \pm 2.1$ & $29.4 \pm 1.9$ & $7.3 \pm 0.7$ & $2.11 \pm 0.16$ \\
L2 & $69.9 \pm 1.1$ & $61.5 \pm 1.7$ & $29.4 \pm 2.7$ & $7.2 \pm 0.7$ & $2.09 \pm 0.17$ \\
H0 & $68.1 \pm 0.9$ & $54.9 \pm 1.7$ & $35.1 \pm 2.1$ & $6.4 \pm 0.6$ & $1.56 \pm 0.15$ \\
H1 & $68.0 \pm 1.3$ & $54.0 \pm 1.8$ & $37.3 \pm 2.2$ & $6.7 \pm 0.9$ & $1.45 \pm 0.16$ \\
H2 & $67.5 \pm 0.7$ & $53.4 \pm 1.4$ & $37.8 \pm 1.3$ & $5.9 \pm 0.5$ & $1.41 \pm 0.11$ \\
ANOVA & & & & & \\
CLA & 0.5281 & 0.4150 & 0.1676 & 0.0799 & 0.4372 \\
Oil & $<0.0001$ & $<0.0001$ & $<0.0001$ & $<0.0001$ & $<0.0001$ \\
Interact. & 0.4674 & 0.1428 & 0.0589 & 0.2215 & 0.1118 \\
\hline
\end{tabular}

Values are means \pm SD of 12 fish. Significance (P valuers) of effects of CLA, oil content and their interaction were determined two-way ANOVA as described in the Materials and methods. CLA, conjugated linoleic acid; P:L, protein:lipid ratio.

$\mathrm{H} 0, \mathrm{H} 1$ and $\mathrm{H} 2$, diets containing fish oil at $34 \%$ and supplemented with 0,1 and $2 \%$ CLA; L0 ,L1 and L2, diets containing fish oil at 17\% and supplemented with 0,1 and $2 \%$ CLA. 
Table 5. Lipid content (percentage of wet wt) of liver and flesh from Atlantic salmon (Salmo salar) fed CLA

\begin{tabular}{lcc}
\hline Diet & Liver & Flesh \\
\hline L0 & $3.28 \pm 0.28$ & $3.12 \pm 0.39$ \\
L1 & $3.37 \pm 0.14$ & $3.20 \pm 0.45$ \\
L2 & $3.45 \pm 0.20$ & $3.22 \pm 0.41$ \\
H0 & $3.50 \pm 0.20$ & $3.90 \pm 0.78$ \\
H1 & $3.64 \pm 0.20$ & $4.45 \pm 0.53$ \\
H2 & $3.76 \pm 0.24$ & $4.98 \pm 0.23$ \\
ANOVA & & \\
CLA & 0.0636 & 0.0231 \\
Oil & 0.0008 & $<0.0001$ \\
Interact. & 0.8762 & 0.0676 \\
\hline
\end{tabular}

Values are means \pm SD of 6 samples each of tissue pooled

from 3 fish. Significance (P values) of effects of CLA, oil content an their interaction were determined by two -way ANOVA as described in the Materials and Methods. CLA, conjugated linoleic acid. $\mathrm{H} 0, \mathrm{H} 1$ and $\mathrm{H} 2$, diets containing fish oil at $34 \%$ and supplemented with 0, 1 and 2\% CLA; L0 ,L1 and L2, diets containing fish oil at $17 \%$ and supplemented with 0,1 and $2 \%$ CLA. 
Table 6. Lipid class composition (percentage of total lipid) of liver of Atlantic salmon (Salmo salar ) fed CLA

\begin{tabular}{lccccccc}
\hline Lipid class & \multicolumn{2}{c}{ L0 } & L1 & L2 & H0 & H1 & H2 \\
\hline PC & $29.8 \pm 0.9$ & $28.2 \pm 3.8$ & $30.1 \pm 2.4$ & $28.2 \pm 2.1$ & $25.3 \pm 2.2$ & $24.7 \pm 1.2$ \\
PE & $17.1 \pm 0.4$ & $17.7 \pm 1.0$ & $17.5 \pm 0.9$ & $17.5 \pm 0.9$ & $15.0 \pm 0.6$ & $14.4 \pm 0.9$ \\
PS & $4.1 \pm 0.5$ & $4.1 \pm 0.8$ & $4.1 \pm 0.8$ & $3.6 \pm 0.5$ & $3.2 \pm 0.2$ & $3.2 \pm 0.1$ \\
PI & $5.8 \pm 0.8$ & $6.0 \pm 0.7$ & $5.7 \pm 0.8$ & $5.6 \pm 0.4$ & $5.4 \pm 0.3$ & $4.9 \pm 0.6$ \\
PG/CL & $4.7 \pm 0.2$ & $4.8 \pm 0.4$ & $4.5 \pm 0.4$ & $4.5 \pm 0.2$ & $3.9 \pm 0.3$ & $3.5 \pm 0.3$ \\
Sphingomyelin & $4.8 \pm 0.8$ & $4.7 \pm 0.9$ & $4.8 \pm 0.8$ & $4.2 \pm 0.6$ & $3.7 \pm 0.3$ & $3.8 \pm 0.3$ \\
Lyso-PC & $0.9 \pm 0.6$ & $0.7 \pm 0.3$ & $0.8 \pm 0.2$ & $0.9 \pm 0.4$ & $0.7 \pm 0.2$ & $0.7 \pm 0.1$ \\
Total polar & $67.2 \pm 3.9$ & $66.2 \pm 6.6$ & $67.4 \pm 5.8$ & $64.5 \pm 3.4$ & $57.2 \pm 3.2$ & $55.3 \pm 2.2$ \\
Total neutral & $32.8 \pm 3.9$ & $33.8 \pm 6.6$ & $32.6 \pm 5.8$ & $35.5 \pm 3.4$ & $42.8 \pm 3.3$ & $44.7 \pm 2.2$ \\
Cholesterol & $18.3 \pm 0.9$ & $18.2 \pm 1.5$ & $18.8 \pm 0.3$ & $18.0 \pm 0.6$ & $15.4 \pm 1.8$ & $15.1 \pm 1.2$ \\
Triacylglycerol & $12.3 \pm 4.7$ & $13.4 \pm 8.5$ & $11.9 \pm 5.8$ & $15.4 \pm 3.8$ & $25.7 \pm 4.7$ & $27.3 \pm 3.8$ \\
Free fatty acid & $2.2 \pm 0.6$ & $2.1 \pm 0.5$ & $1.9 \pm 1.0$ & $2.1 \pm 1.2$ & $1.7 \pm 0.6$ & $2.3 \pm 0.7$ \\
Steryl ester & tr & tr & tr & tr & tr & tr \\
\hline
\end{tabular}

Values are means \pm SD of 6 samples each of tissue pooled from 3 fish. CL, cardiolipin; CLA, conjugated linoleic acid; PC, phosphatidylcholine; PE, phosphatidylethanolamine; PG, phosphatidylglycerol; PI, phosphatidylinositol; PS, phosphatidylserine; trace, $<0.5 \%$. 
Table 7. Lipid class composition (percentage of total lipid) of flesh of Atlantic salmon (Salmo salar ) fed CLA

\begin{tabular}{lccccccc}
\hline Lipid class & \multicolumn{2}{c}{ L0 } & L1 & L2 & H0 & H1 & H2 \\
\hline PC & $8.6 \pm 1.0$ & $8.2 \pm 0.6$ & $8.1 \pm 1.0$ & $8.0 \pm 0.5$ & $7.4 \pm 0.5$ & $7.3 \pm 0.9$ \\
PE & $6.9 \pm 0.9$ & $6.5 \pm 0.9$ & $6.0 \pm 0.6$ & $5.6 \pm 0.7$ & $5.3 \pm 0.5$ & $5.0 \pm 0.5$ \\
PS & $0.8 \pm 0.2$ & $0.7 \pm 0.2$ & $0.6 \pm 0.2$ & $0.5 \pm 0.1$ & $0.5 \pm 0.1$ & $0.6 \pm 0.2$ \\
PI & $3.4 \pm 0.5$ & $3.0 \pm 0.5$ & $2.7 \pm 0.6$ & $2.2 \pm 0.3$ & $2.0 \pm 0.2$ & $1.8 \pm 0.2$ \\
PG/CL & $1.4 \pm 0.4$ & $1.5 \pm 0.5$ & $1.4 \pm 0.3$ & $1.2 \pm 0.2$ & $1.1 \pm 0.2$ & $1.1 \pm 0.1$ \\
Sphingomyelin & $0.6 \pm 0.2$ & $0.6 \pm 0.2$ & $0.5 \pm 0.1$ & $0.4 \pm 0.1$ & $0.4 \pm 0.0$ & $0.4 \pm 0.1$ \\
Lyso-PC & $2.6 \pm 0.4$ & $1.7 \pm 0.4$ & $1.6 \pm 0.5$ & $1.4 \pm 0.4$ & $1.1 \pm 0.3$ & $1.0 \pm 0.1$ \\
Total polar & $24.3 \pm 2.7$ & $22.3 \pm 2.4$ & $20.9 \pm 2.8$ & $19.3 \pm 1.7$ & $17.6 \pm 1.4$ & $17.2 \pm 1.7$ \\
Total neutral & $75.7 \pm 2.7$ & $77.7 \pm 2.4$ & $79.1 \pm 2.8$ & $80.7 \pm 1.7$ & $82.4 \pm 1.4$ & $82.8 \pm 1.7$ \\
Cholesterol & $9.3 \pm 0.3$ & $8.8 \pm 0.5$ & $8.7 \pm 0.5$ & $8.5 \pm 0.7$ & $8.4 \pm 0.4$ & $8.3 \pm 0.3$ \\
Triacylglycerol & $53.4 \pm 3.0$ & $56.4 \pm 3.0$ & $59.5 \pm 3.9$ & $62.0 \pm 3.4$ & $65.4 \pm 2.5$ & $66.0 \pm 2.0$ \\
Free fatty acid & $13.0 \pm 1.3$ & $12.5 \pm 1.1$ & $11.0 \pm 1.1$ & $10.2 \pm 2.8$ & $8.6 \pm 0.8$ & $8.5 \pm 0.4$ \\
\hline
\end{tabular}

Values are means \pm SD of 6 samples each of tissue pooled from 3 fish. CL, cardiolipin; CLA, conjugated linoleic acid; PC, phosphatidylcholine; PE, phosphatidylethanolamine; PG, phosphatidylglycerol; PI, phosphatidylinositol; PS, phosphatidylserine. 
Table 8. Significance (P values) of effects of dietary conjugated linoleic acid (CLA) ar oil content (Oil), and their interaction (Interact.) as determined by two-way ANOVA a described in the Methods section.

\begin{tabular}{|c|c|c|c|c|c|c|}
\hline & \multicolumn{3}{|c|}{ Liver } & \multicolumn{3}{|c|}{ Flesh } \\
\hline & CLA & Oil & Iteract. & CLA & Oil & Interact. \\
\hline \multicolumn{7}{|l|}{ Lipid classes } \\
\hline $\mathrm{PC}$ & 0.0625 & 0.0002 & 0.1379 & 0.1493 & 0.0086 & 0.9368 \\
\hline $\mathrm{PE}$ & 0.0008 & $<0.0001$ & $<0.0001$ & 0.0461 & $<0.0001$ & 0.8687 \\
\hline PS & 0.5971 & 0.0002 & 0.5971 & 0.7192 & 0.0072 & 0.1143 \\
\hline PI & 0.216 & 0.0165 & 0.5017 & 0.0107 & $<0.0001$ & 0.6688 \\
\hline $\mathrm{PG} / \mathrm{CL}$ & 0.0002 & $<0.0001$ & 0.0069 & 0.9036 & 0.0075 & 0.7393 \\
\hline Sphingomyelin & 0.535 & 0.0005 & 0.6972 & 0.5852 & 0.0009 & 0.5852 \\
\hline Lyso-PC & 0.3414 & 0.7717 & 0.9181 & 0.0001 & $<0.0001$ & 0.0907 \\
\hline Total polar & 0.0341 & $<0.0001$ & 0.0441 & 0.0139 & $<0.0001$ & 0.7494 \\
\hline Total neutral & 0.0341 & $<0.0001$ & 0.0441 & 0.0139 & $<0.0001$ & 0.7494 \\
\hline Cholesterol & 0.0154 & $<0.0001$ & 0.0036 & 0.1131 & 0.0019 & 0.4941 \\
\hline Triacylglycerol & 0.0212 & $<0.0001$ & 0.0263 & 0.0012 & $<0.0001$ & 0.5606 \\
\hline Free fatty acids & 0.7264 & 0.9021 & 0.4793 & 0.0148 & $<0.0001$ & 0.4733 \\
\hline \multicolumn{7}{|l|}{ Fatty acids } \\
\hline $14: 0$ & 0.0042 & $<0.0001$ & 0.1530 & 0.1205 & $<0.0001$ & 0.1950 \\
\hline $16: 0$ & 0.0224 & 0.0043 & 0.8540 & 0.0008 & 0.0293 & 0.2091 \\
\hline $18: 0$ & 0.0238 & $<0.0001$ & 0.7143 & 0.0825 & $<0.0001$ & 0.8675 \\
\hline Total saturated & 0.2904 & 0.6673 & 0.4691 & 0.0187 & 0.0112 & 0.3098 \\
\hline $16: 1 n-7$ & 0.0031 & $<0.0001$ & 0.1530 & $<0.0001$ & $<0.0001$ & 0.0649 \\
\hline $18: 1 n-9$ & 0.0146 & 0.1128 & 0.8156 & 0.0008 & $<0.0001$ & 0.5323 \\
\hline $18: 1 \mathrm{n}-7$ & 0.1530 & 0.0002 & 1.000 & 0.0010 & 0.0009 & 0.1304 \\
\hline $20: 1 n-9$ & 0.0649 & 0.0561 & 0.0145 & 0.8284 & 0.4568 & 0.1022 \\
\hline $22: 1 n-11$ & 0.1460 & 0.0004 & 0.3442 & 0.1296 & 0.0979 & 0.0061 \\
\hline 24:1n-9 & $<0.0001$ & 1.0000 & 0.1229 & 0.2394 & 1.0000 & 0.2394 \\
\hline Total monoenes & 0.0206 & 0.1747 & 0.3679 & 0.7342 & 0.4586 & 0.2031 \\
\hline $18: 2 n-6$ & 0.4345 & $<0.0001$ & 0.0932 & 0.0649 & $<0.0001$ & 0.0088 \\
\hline $20: 4 n-6$ & 0.1315 & 0.5249 & 0.4930 & 0.4810 & 0.0935 & 0.4810 \\
\hline CLA $(9 \mathrm{c}, 11 \mathrm{t})$ & $<0.0001$ & $<0.0001$ & 0.0001 & $<0.0001$ & $<0.0001$ & $<0.0001$ \\
\hline CLA $(10 t, 12 c)$ & $<0.0001$ & $<0.0001$ & $<0.0001$ & $<0.0001$ & $<0.0001$ & $<0.0001$ \\
\hline $18: 3 n-3$ & 0.0195 & $<0.0001$ & 0.2394 & $<0.0001$ & $<0.0001$ & 0.1530 \\
\hline $18: 4 n-3$ & 0.0859 & 0.0003 & 0.0859 & $<0.0001$ & $<0.0001$ & 0.2394 \\
\hline $20: 4 n-3$ & 0.3798 & $<0.0001$ & 0.3798 & 0.0003 & $<0.0001$ & 0.0195 \\
\hline $20: 5 n-3$ & 0.0851 & $<0.0001$ & 0.5323 & $<0.0001$ & $<0.0001$ & 0.1190 \\
\hline $22: 5 n-3$ & 0.1785 & $<0.0001$ & 0.1785 & 0.0006 & $<0.0001$ & 0.0712 \\
\hline $22: 6 n-3$ & 0.5863 & 0.0046 & 0.3651 & 0.0018 & 0.1102 & 0.6440 \\
\hline Total n-3PUFA & 0.138 & 0.0214 & 0.2188 & 0.0002 & $<0.0001$ & 0.4302 \\
\hline
\end{tabular}

CL, cardiolipin; PC, phosphatidylcholine; PE, phosphatidylethanolamine;

PG, phosphatidylglycerol; PI, phosphatidylinositol; PS, phosphatidylserine;

PUFA, polyunsaturated fatty acids. 
Table 9. Fatty acid composition (percentage of weight) of total lipid from liver of Atlantic salmon (Salmo salar ) fed conjugated linoleic acid (CLA)

\begin{tabular}{|c|c|c|c|c|c|c|}
\hline & L0 & $\mathrm{L} 1$ & L2 & $\mathrm{HO}$ & $\mathrm{H} 1$ & $\mathrm{H} 2$ \\
\hline $14: 0$ & $1.6 \pm 0.1$ & $1.5 \pm 0.1$ & $1.3 \pm 0.2$ & $2.3 \pm 0.5$ & $1.8 \pm 0.2$ & $1.9 \pm 0.2$ \\
\hline $16: 0$ & $18.5 \pm 1.3$ & $17.8 \pm 1.2$ & $17.1 \pm 0.9$ & $19.4 \pm 0.9$ & $18.7 \pm 0.9$ & $18.4 \pm 0.7$ \\
\hline 18:0 & $8.3 \pm 1.0$ & $8.8 \pm 1.1$ & $8.9 \pm 0.8$ & $6.3 \pm 0.3$ & $7.1 \pm 0.4$ & $7.4 \pm 0.5$ \\
\hline Total saturated ${ }^{1}$ & $29.0 \pm 1.3$ & $28.8 \pm 1.3$ & $27.8 \pm 0.7$ & $28.6 \pm 1.1$ & $28.2 \pm 1.2$ & $28.3 \pm 1.2$ \\
\hline $16: 1 n-7^{2}$ & $2.3 \pm 0.1$ & $2.2 \pm 0.3$ & $2.0 \pm 0.2$ & $3.2 \pm 0.5$ & $2.6 \pm 0.3$ & $2.6 \pm 0.3$ \\
\hline $18: 1 n-9$ & $9.6 \pm 1.0$ & $8.8 \pm 0.4$ & $9.4 \pm 0.6$ & $9.4 \pm 1.0$ & $8.2 \pm 0.8$ & $8.9 \pm 0.8$ \\
\hline $18: 1 n-7$ & $2.4 \pm 0.1$ & $2.3 \pm 0.1$ & $2.3 \pm 0.1$ & $2.6 \pm 0.2$ & $2.5 \pm 0.2$ & $2.5 \pm 0.1$ \\
\hline $20: 1 n-9^{3}$ & $1.8 \pm 0.2$ & $1.8 \pm 0.1$ & $1.6 \pm 0.2$ & $2.1 \pm 0.4$ & $1.6 \pm 0.3$ & $2.0 \pm 0.2$ \\
\hline $22: 1 \mathrm{n}-11^{4}$ & $0.5 \pm 0.1$ & $0.4 \pm 0.3$ & $0.6 \pm 0.2$ & $1.0 \pm 0.4$ & $0.7 \pm 0.2$ & $0.8 \pm 0.2$ \\
\hline $24: 1 n-9$ & $1.1 \pm 0.1$ & $1.0 \pm 0.2$ & $0.8 \pm 0.1$ & $1.1 \pm 0.2$ & $0.9 \pm 0.0$ & $0.9 \pm 0.1$ \\
\hline Total monoenes & $17.7 \pm 1.5$ & $16.7 \pm 1.0$ & $16.6 \pm 1.4$ & $19.3 \pm 2.4$ & $16.4 \pm 1.7$ & $17.6 \pm 1.6$ \\
\hline $18: 2 n-6$ & $2.8 \pm 0.2$ & $2.9 \pm 0.2$ & $3.0 \pm 0.2$ & $1.9 \pm 0.2$ & $1.7 \pm 0.2$ & $1.8 \pm 0.1$ \\
\hline $20: 4 n-6$ & $3.6 \pm 0.4$ & $3.7 \pm 0.2$ & $3.7 \pm 0.2$ & $3.5 \pm 0.4$ & $3.9 \pm 0.3$ & $3.8 \pm 0.3$ \\
\hline CLA $(9 \mathrm{c}, 11 \mathrm{t})$ & $0.0 \pm 0.0$ & $0.9 \pm 0.2$ & $1.8 \pm 0.2$ & $0.0 \pm 0.0$ & $0.6 \pm 0.1$ & $1.2 \pm 0.2$ \\
\hline CLA $(10 t, 12 c)$ & $0.0 \pm 0.0$ & $0.7 \pm 0.1$ & $1.6 \pm 0.2$ & $0.0 \pm 0.0$ & $0.5 \pm 0.1$ & $1.0 \pm 0.2$ \\
\hline Total n-6 PUFA ${ }^{5}$ & $7.9 \pm 0.4$ & $9.8 \pm 0.3$ & $11.7 \pm 0.4$ & $6.5 \pm 0.3$ & $7.8 \pm 0.3$ & $8.9 \pm 0.3$ \\
\hline $18: 3 n-3$ & $0.4 \pm 0.0$ & $0.3 \pm 0.1$ & $0.3 \pm 0.1$ & $0.5 \pm 0.1$ & $0.5 \pm 0.1$ & $0.4 \pm 0.0$ \\
\hline $18: 4 n-3$ & $0.2 \pm 0.1$ & $0.2 \pm 0.1$ & $0.2 \pm 0.1$ & $0.5 \pm 0.2$ & $0.3 \pm 0.1$ & $0.3 \pm 0.1$ \\
\hline $20: 4 n-3$ & $0.6 \pm 0.1$ & $0.6 \pm 0.1$ & $0.6 \pm 0.1$ & $1.0 \pm 0.1$ & $1.0 \pm 0.1$ & $0.9 \pm 0.1$ \\
\hline $20: 5 n-3$ & $8.4 \pm 0.7$ & $8.3 \pm 0.6$ & $7.9 \pm 0.3$ & $10.2 \pm 0.6$ & $10.6 \pm 0.3$ & $10.0 \pm 0.5$ \\
\hline $22: 5 n-3$ & $2.7 \pm 0.2$ & $2.5 \pm 0.3$ & $2.4 \pm 0.1$ & $3.0 \pm 0.2$ & $3.1 \pm 0.2$ & $2.8 \pm 0.1$ \\
\hline $22: 6 n-3$ & $33.0 \pm 1.3$ & $32.6 \pm 0.8$ & $32.5 \pm 1.3$ & $30.3 \pm 2.3$ & $31.9 \pm 1.9$ & $30.7 \pm 2.1$ \\
\hline Total n-3 PUFA ${ }^{6}$ & $45.4 \pm 2.0$ & $44.7 \pm 0.9$ & $43.9 \pm 1.3$ & $45.6 \pm 2.5$ & $47.6 \pm 1.6$ & $45.3 \pm 2.3$ \\
\hline
\end{tabular}

Values are means \pm SD of 6 samples each of tissue pooled from 3 fish. PUFA, polyunsaturated fatty acids.

${ }^{1}$, contains 15:0 and 20:0, present in some samples at up to $0.4 \%{ }^{2}{ }^{2}$, contains n-9 isomer; ${ }^{3}$, contains n-7 isomer;

${ }^{4}$, contains n-9 isomer; ${ }^{5}$, totals include 18;3n-6, 20:2n-6, 20:3n-6, 22:4n-6 and 22:5n-6 present in some samples at up to $0.6 \%{ }^{6}$, contains $20: 3 \mathrm{n}-3$ present at up to $0.1 \%$. $\mathrm{H} 0, \mathrm{H} 1$ and $\mathrm{H} 2$, diets containing fish oil at $34 \%$ and supplemented with 0,1 and 2\% CLA; L0,L1 and L2, diets containing fish oil at 17\% and supplemented with 0, 1 and 2\% CLA. 
Table 10. Fatty acid composition (percentage of weight) of total lipid from flesh of Atlantic salmon (Salmo salar : fed conjugated linoleic acid (CLA)

\begin{tabular}{|c|c|c|c|c|c|c|}
\hline & L0 & L1 & L2 & $\mathrm{HO}$ & $\mathrm{H} 1$ & $\mathrm{H} 2$ \\
\hline 14:0 & $3.8 \pm 0.2$ & $3.7 \pm 0.6$ & $3.3 \pm 0.2$ & $4.2 \pm 0.3$ & $4.3 \pm 0.3$ & $4.2 \pm 0.2$ \\
\hline $16: 0$ & $18.4 \pm 0.3$ & $18.1 \pm 1.4$ & $16.7 \pm 0.4$ & $17.3 \pm 0.6$ & $17.5 \pm 0.7$ & $16.7 \pm 0.5$ \\
\hline 18:0 & $5.2 \pm 0.2$ & $5.4 \pm 0.5$ & $5.3 \pm 0.2$ & $4.1 \pm 0.2$ & $4.4 \pm 0.2$ & $4.3 \pm 0.1$ \\
\hline Total saturated $^{1}$ & $28.2 \pm 0.5$ & $28.1 \pm 2.5$ & $26.2 \pm 0.7$ & $26.3 \pm 0.9$ & $26.9 \pm 1.1$ & $25.9 \pm 0.7$ \\
\hline $16: 1 n-7^{2}$ & $5.2 \pm 0.2$ & $5.2 \pm 0.3$ & $4.7 \pm 0.1$ & $6.3 \pm 0.2$ & $6.2 \pm 0.2$ & $6.0 \pm 0.2$ \\
\hline 18:1n-9 & $14.9 \pm 0.4$ & $15.6 \pm 0.7$ & $16.0 \pm 0.4$ & $14.2 \pm 0.8$ & $14.4 \pm 0.4$ & $15.0 \pm 0.4$ \\
\hline $18: 1 n-7$ & $3.3 \pm 0.1$ & $3.3 \pm 0.2$ & $3.0 \pm 0.0$ & $3.4 \pm 0.1$ & $3.4 \pm 0.2$ & $3.3 \pm 0.1$ \\
\hline $20: 1 n-9^{3}$ & $4.6 \pm 0.4$ & $4.8 \pm 0.5$ & $4.4 \pm 0.2$ & $4.8 \pm 0.3$ & $4.5 \pm 0.4$ & $4.8 \pm 0.5$ \\
\hline $22: \ln -11^{4}$ & $3.9 \pm 0.4$ & $4.2 \pm 0.4$ & $3.8 \pm 0.2$ & $4.1 \pm 0.3$ & $3.9 \pm 0.2$ & $4.0 \pm 0.3$ \\
\hline 24:1n-9 & $0.7 \pm 0.2$ & $0.7 \pm 0.2$ & $0.7 \pm 0.1$ & $0.8 \pm 0.1$ & $0.7 \pm 0.1$ & $0.6 \pm 0.1$ \\
\hline Total monoenes & $32.7 \pm 1.5$ & $34.0 \pm 2.2$ & $32.6 \pm 0.8$ & $33.7 \pm 1.5$ & $33.1 \pm 1.3$ & $33.6 \pm 1.1$ \\
\hline $18: 2 n-6$ & $5.2 \pm 0.2$ & $5.2 \pm 0.2$ & $4.9 \pm 0.2$ & $3.4 \pm 0.1$ & $3.3 \pm 0.1$ & $3.4 \pm 0.0$ \\
\hline $20: 4 n-6$ & $0.8 \pm 0.1$ & $0.7 \pm 0.1$ & $0.7 \pm 0.0$ & $0.8 \pm 0.1$ & $0.8 \quad 0.1$ & $0.8 \pm 0.2$ \\
\hline CLA $(9 \mathrm{c}, 11 \mathrm{t})$ & $0.0 \pm 0.0$ & $1.9 \pm 0.2$ & $3.7 \pm 0.4$ & $0.0 \pm 0.0$ & $1.1 \pm 0.1$ & $2.2 \pm 0.2$ \\
\hline CLA $(10 t, 12 c)$ & $0.0 \pm 0.0$ & $1.6 \pm 0.2$ & $3.2 \pm 0.4$ & $0.0 \pm 0.0$ & $1.0 \pm 0.1$ & $2.0 \pm 0.2$ \\
\hline Total n-6 PUFA & $7.2 \pm 0.3$ & $10.5 \pm 0.7$ & $13.6 \pm 1.0$ & $5.2 \pm 0.3$ & $7.3 \pm 0.4$ & $9.5 \pm 0.5$ \\
\hline $18: 3 n-3$ & $1.0 \pm 0.0$ & $0.9 \pm 0.1$ & $0.8 \pm 0.0$ & $1.1 \pm 0.0$ & $1.0 \pm 0.1$ & $1.0 \pm 0.1$ \\
\hline $18: 4 n-3$ & $1.4 \pm 0.0$ & $1.3 \pm 0.1$ & $1.2 \pm 0.1$ & $1.8 \pm 0.1$ & $1.8 \pm 0.1$ & $1.6 \pm 0.0$ \\
\hline $20: 4 n-3$ & $1.1 \pm 0.1$ & $0.9 \pm 0.1$ & $0.9 \pm 0.0$ & $1.2 \pm 0.1$ & $1.2 \pm 0.1$ & $1.1 \pm 0.0$ \\
\hline $20: 5 n-3$ & $7.2 \pm 0.3$ & $6.1 \pm 1.0$ & $5.9 \pm 0.1$ & $8.5 \pm 0.5$ & $8.3 \pm 0.4$ & $7.6 \pm 0.3$ \\
\hline $22: 5 n-3$ & $2.8 \pm 0.1$ & $2.3 \pm 0.4$ & $2.4 \pm 0.1$ & $3.2 \pm 0.2$ & $3.1 \pm 0.2$ & $2.9 \pm 0.1$ \\
\hline $22: 6 n-3$ & $18.2 \pm 1.4$ & $15.5 \pm 2.5$ & $16.0 \pm 1.3$ & $18.6 \pm 1.5$ & $17.0 \pm 1.2$ & $16.6 \pm 0.5$ \\
\hline Total n-3 PUFA ${ }^{6}$ & $31.9 \pm 1.8$ & $27.4 \pm 4.1$ & $27.5 \pm 1.2$ & $34.8 \pm 2.2$ & $32.6 \pm 1.6$ & $31.0 \pm 0.8$ \\
\hline
\end{tabular}

Values are means \pm SD of 6 samples each of tissue pooled from 3 fish. PUFA, polyunsaturated fatty acids.

', contains 15:0, 20:0 and 22:0, present in some samples at up to $0.5 \% ;^{2}$, contains $n-9$ isomer; ${ }^{3}$, contains n-7 isomer; ${ }^{4}$, contains n-9 isomer; ${ }^{5}$, totals include 18:3n-6, 20:2n-6, 20:3n-6, 22:4n-6 and 22:5n-6 present in some samples at up to $0.5 \%$; ${ }^{6}$, contains $20: 3 \mathrm{n}-3$ present at up to $0.5 \%$. $\mathrm{H} 0, \mathrm{H} 1$ and $\mathrm{H} 2$, diets containing fish oil at $34 \%$ and supplemented with 0, 1 and 2\% CLA; L0,L1 and L2, diets containing fish oil at 17\% and supplemented with 0, 1 and 2\% CLA. 